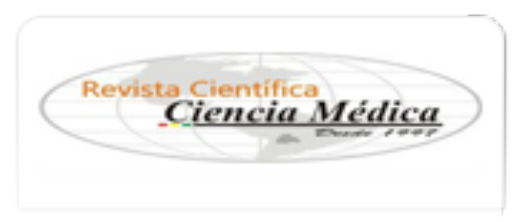

Revista Científica Ciencia Médica

ISSN: 1817-7433

ISSN: 2220-2234

revista_cienciamedica@hotmail.com

Universidad Mayor de San Simón

Bolivia

Mamani Ortiz, Yercin

El aporte de los comités editoriales de revistas científicas editadas por universidades

Revista Científica Ciencia Médica, vol. 22, núm. 2, 2019, Julio-, pp. 3-4

Universidad Mayor de San Simón

Cochabamba, Bolivia

Disponible en: http://www.redalyc.org/articulo.oa?id=426062617007

Cómo citar el artículo

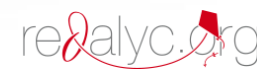

Número completo

Más información del artículo

Página de la revista en redalyc.org

Sistema de Información Científica Redalyc Red de Revistas Científicas de América Latina y el Caribe, España y Portugal Proyecto académico sin fines de lucro, desarrollado bajo la iniciativa de acceso abierto 
PÁGINA DEL EDITOR

\title{
El APORTE DE LOS COMITÉS EDITORIALES DE REVISTAS CIENTífICAS EDITADAS POR UNIVERSIDADES.
}

\author{
THE CONTRIBUTION OF THE EDITORIAL BOARD OF SCIENTIFIC JOURNALS EDITED BY UNIVERSITIES.
}

\section{Yercin Mamani Ortiz ${ }^{1,2}$}

Cuando se analiza el rol de la universidad en la sociedad, todos coinciden en que además de la formación de capital humano capacitado y/o especializado, uno de sus pilares fundamentales es la generación de conocimiento científico, su difusión mediante publicaciones de carácter académico o científico, contribuyendo a la producción científica local, respondiendo a los problemas de su contexto y sirviendo de base para la generación de cambios en la sociedad en cualquiera de las áreas de conocimiento y desarrollo social.

En el campo de la salud, encontramos diferentes tipos de revistas científicas, siendo las más conocidas, aquellas asociadas a sociedades científicas independientes, las revistas solventadas por las universidades, aquellos que son financiadas por centros de investigación privados y las editoriales científicas internacionales comerciales como Springer, Elservier, PLOS, etc. Que actualmente tienen el liderazgo mundial en la comunicación científica en salud; excluyendo las revistas predadoras o revistas falsas, que no cumplen con los criterios mínimos de selección y difusión, incluyendo muchos artículos con información falsa o plagiada.

Para editar de manera óptima una revista científica, además del servicio editorial o comercial para la difusión de la revista y los artículos publicados en ella; también se necesita recursos humanos académicos y técnicos de alto nivel de formación y experiencia en investigación científica que permitan un proceso de selección, revisión y aprobación editorial óptimo para cada uno de los tipos de artículos que se publican. La sinergia de ambos genera un sistema de gestión que le permite a la revista no solo posicionarse en la comunidad científica, sino asegurar la utilización del conocimiento científico difundido, uno de los puntos claves en la evaluación del factor de impacto que cada vez es más usado como indicador de calidad de una revista científica.

La ventaja de las revistas cuyos comités editoriales son parte de una universidad, es que generalmente no requieren buscar externamente al personal académico que lidere la revista, así como el comité editorial o equipo editorial, sin embargo no existe suficiente capacidad para difundir o vender sus revistas a nivel nacional o internacional, además no se tienen mecanismos de reconocimiento a los profesores que se dedican a editar revistas o participan del proceso editorial; contrario a las revistas internacionales comerciales, que requieren buscar el personal académico en universidades, porque no son entidades formadoras de recurso humano calificado, pero tienen la ventaja de contar con servicios editoriales profesionalizados, en todos los casos con un reconocimiento científico $y$ una remuneración económica para quienes participan del comité editorial, siendo las que lideran la difusión de conocimiento científico a nivel internacional.

El aporte de una revista científica editada en una universidad representa un contribución desde el campo docente, para quienes el ser parte de un comité editorial de una revista científica representa un espacio de aprendizaje y actualización docente, que los mantiene en contacto con la información científica, se convierte en una escuela de formación en la generación y evaluación del conocimiento científico, por ello que algunas corrientes sugieren que las escuelas de postgrado cuenten con sus propias revistas científicas, para promover el aprendizaje, aplicación y difusión del conocimiento científico.

Por otra parte, está el aporte de la revista científica en la difusión del conocimiento científico generado por la propia universidad, representa un espacio de posicionamiento institucional frente a la comunidad científica y la población general; por lo que, la calidad de una revista editada en una universidad representa en parte la calidad en la 
formación científica de sus integrantes, incluyendo tanto docentes como estudiantes.

Finalmente, los comités editoriales de revistas editadas en universidades generan un aporte estructural basado en cualificar la producción de conocimiento, porque regulan $y$ evalúa la calidad de la producción científica, generando un sistema de colaboración con otras universidades, otros investigadores a nivel nacional e internacional, otorgando un valor agregado a la producción local mediante la certificación de calidad a cada uno de los artículos publicados en ella, para su utilización por la comunidad académica, científica y las autoridades que toman esta información para la generación,

\footnotetext{
${ }^{1,2}$ Yercin Mamani Ortiz

${ }^{1}$ Comité Editorial Revista Científica "Ciencia Médica". Facultad de Medicina "Dr. Aurelio Melean", Universidad Mayor de San Simón. CochabambaBolivia

${ }^{2}$ Investigador en Instituto de Investigaciones Biomédicas e Investigación Social Medicina (IIBISMED-UMSS)
}

Correspondencia a: Yercin Mamani Ortiz Correo electronico: yercin2003@hotmail. com ORCID ID: https://orcid.org/0000-00030400-0414 adecuación e implementación de planes, programas sociales y/o políticas públicas en salud.

Actualmente solo 4 revistas bolivianas en el área de salud se encuentran indexadas en Scielo (Scientific Electronic Library Online), de las cuales 3 son editadas por Universidades y 2 corresponden a la Facultad de Medicina de la Universidad Mayor de San Simón; la Gaceta Médica Boliviana y nuestra Revista Científica Ciencia Médica, denotando los esfuerzos para mejorar la difusión y visibilidad del conocimiento científico generado en nuestra universidad, en conexión con otros autores de Latinoamérica, el Caribe, España, Portugal y otros países europeos; de esta manera, contribuyen al posicionamiento internacional de nuestra unidad académica; y por todo lo anterior, es imperativo que los comités o equipos editoriales de nuestras revistas científicas, reciban el soporte institucional acordes con la contribución que realizan en el campo académico, científico y estructural. Esperamos que las autoridades actuales puedan consolidar el apoyo relacionado con servicio editorial, el manejo de las plataformas virtuales necesarias para mantener los altos estándares implicados en los procesos de indexación y los ambientes necesarios para poder trabajar acorde a las exigencias de los procesos de recepción, revisión, evaluación y difusión del conocimiento científico
Citar como:

Mamani Y. El aporte de los comites editoriales de revistas cientificas editadas por universidades. Rev Cient Cienc Med. 2019; 22(2): 3-4 